《Research Note》

\title{
Tylosin Levels in Egg of Laying Hen Given Medicated Drinking Water
}

\author{
Yoshikazu Iritani, Shigetada Hidaka, Tetsuo Kitabatake* \\ and Shigeru SASAKI* \\ Aburahi Laboratories, Shionogi \& Co., Ltd., Shiga-ken \\ *Animal Health Product, Shionogi \& Co., Ltd., Osaka
}

Tylosin, a macroride antibiotic, is widely used for fowls as a feed additive and in drinking water ${ }^{1}$. Its safety for animals has been well documented ${ }^{3,3)}$ Moreover, YosHIDA et $a l .{ }^{4)}$ reported that tylosin was not detected in the egg of laying hen given as a feed additive at the recommended dose. However, the concentration of tylosin given to birds to cure diseases is higher. In addition, the treatments cover very short periods of time than that of a feed additive.

This paper describes the residue of tylosin in eggs of hens given medicated drinking water at a dose practical for disease control.

\section{Experimental}

Birds, 140-day-old White Leghorn laying hens were given a feed free of antibiotics froom seven days before the experiments. They were divided four groups of 5 to 7 birds per a group. The medicated group received drinking water containing $0.05 \%$ Tylocine (Tylosin tartrate, Shionogi and Co., Ltd.) for one, three or five days respectively. The control group received no medication. A tray of the drinking water was suplied to every medicated group.

Four $\mathrm{m} l$ of a mixture of egg white and egg yolk from these birds was added $10 \mathrm{~m} l$ of phosphate buffer ( $\mathrm{pH} 8.0$ ) composed of $0.8 \% \mathrm{NaCl}$ solution and methanol $(3: 7)$. Tylosin was extracted from this mixture by the previously described method. ${ }^{5}$ Tylosin content in the eggs was determined microbiologically by the cylinder cup method using Sarcina lutea ATCC 9341. The samples were stocked at $-20^{\circ} \mathrm{C}$ until being extracted or assayed.

\section{Results and Discussion}

Sensitivity of tylosin content in the eggs obtained in this experiment was $0.15 \mathrm{ppm}$.

Tylosin residues in eggs of laying hens after withdrawal following medication are shown in Table 1. No measurable tylosin was detected in most eggs after withdrawal, except for that found on the first day of the groups medicated for one (No. 1) or three 
Table 1. Tylosin residue in eggs of hens given medicated drinking water

\begin{tabular}{|c|c|c|c|c|c|c|c|c|}
\hline \multirow{3}{*}{$\begin{array}{l}\text { Period of } \\
\text { medication } \\
\quad(\text { day })\end{array}$} & \multirow{3}{*}{$\begin{array}{l}\text { Bird } \\
\text { no. }\end{array}$} & \multicolumn{7}{|c|}{ Content of tylosin $(\mathrm{mcg} / \mathrm{m} l)$} \\
\hline & & \multirow{2}{*}{$\begin{array}{c}\text { Before } \\
\text { medication }\end{array}$} & \multicolumn{6}{|c|}{ Days after withdrawal } \\
\hline & & & 1 & 2 & 3 & 4 & $5-7$ & $8-13$ \\
\hline \multirow{6}{*}{1} & 1 & 0 & 0.24 & & 0 & & 0 & \\
\hline & 2 & 0 & & & & & 0 & 0 \\
\hline & 3 & 0 & 0 & & 0 & & 0 & 0 \\
\hline & 4 & 0 & 0 & & 0 & & 0 & 0 \\
\hline & 5 & 0 & 0 & & & & & \\
\hline & 6 & 0 & & & 0 & & 0 & 0 \\
\hline \multirow{5}{*}{3} & 11 & 0 & 0 & & 0 & & 0 & 0 \\
\hline & 12 & 0 & 0 & & 0 & & & 0 \\
\hline & 13 & 0 & 0 & & & & & 0 \\
\hline & 14 & 0 & 0 & & 0 & & & 0 \\
\hline & 15 & 0 & 1.93 & & & & 0 & 0 \\
\hline \multirow{7}{*}{5} & 21 & 0 & 0 & & 0 & & 0 & \\
\hline & 22 & 0 & 0 & & 0 & & & 0 \\
\hline & 23 & 0 & 0 & 0 & & & & 0 \\
\hline & 24 & 0 & 0 & & 0 & & & 0 \\
\hline & 25 & 0 & 0 & & & 1.12 & 0 & 0 \\
\hline & 26 & 0 & 0 & 0 & & & & 0 \\
\hline & 27 & 0 & 0 & 0 & & & & 0 \\
\hline
\end{tabular}

* Birds were medicated with drinking water containing $0.05 \%$ tylosin.

** Zero means less than $0.15 \mathrm{mcg} / \mathrm{ml}$ of tylosin.

*** Blank means that birds were not laid eggs.

days (No. 15) and on the fourth day of the group medicated for five days (No. 25) Although the results of the unmedicated group are not shown in the table, no measurable tylosin was detected in eggs of this group.

Yoshida et al.4) reported that when a chicken was given a high level of tylosin phosphate as a feed additive, the tylosin content in the egg white decreased rapidly and was not detected at three days after withdrawal, while that in the egg yolk decreased gradually and disappeared after seven days. The amounts of residual tylosin in the egg after withdrawal which we found are essentially similar to their findings. Therefore, if tylosin is is given for a long period of time, its withdrawal from the drinking water at the proper time is important.

\section{References}

1) Huber, W. G.: Advances in Veterinary Sci. and Comparative Med., 15, 101, 1971.

2) Berkmann, R. E., E. A. Richards, R. A. Van Duyn and R. M. Kline: Antimicrob. Agents Annu., $595,1960$.

3) Anderson, R. C., H. M. Worth, R. M. Small and P. N. Harris: Food Cosmet. Toxicol., 4, 1. 1966.

4) Yoshida, M., D. Kubota, S. Yonezawa, H. Nakamura, R. Yamaoka and H. Yoshimura: Japan Poultry Sci., 10, 29, 1973.

5) Iritani, Y., S. Hidaka, T. Kitabatake and J. Isono: Japan Poultry Sci., 12, 24, 1975. 